\title{
Los intérpretes mapuches y el Protectorado de Indígenas (1880-1930): constitución jurídica de la propiedad, traducción y castellanización del Ngulumapu ${ }^{1}$
}

\author{
Jorge Pavez Ojeda ${ }^{2}$ \\ Universidad de Tarapacá, Chile \\ Gertrudis Payàs Puigarnau ${ }^{3}$ \\ Universidad Católica de Temuco, Chile \\ Fernando Ulloa Valenzuela ${ }^{4}$ \\ Investigador independiente, Chile
}

\begin{abstract}
Resumen
A partir de la revisión de varios fondos de archivo y de las Memorias anuales de los Protectores de Indígenas, proponemos el estudio de los sujetos y las prácticas de mediación sociolingüística en las
\end{abstract}

1 Esta investigación es un producto del proyecto Fondecyt Regular 11701419: "Mediación lingüístico-cultural en los ámbitos de contacto mapudungun-castellano derivados del proceso de chilenización de la Araucanía: administración de justicia, producción etnográfica y lingüística y escolarización (1880-1930)". Agradecemos la colaboración de Julieta Vivar en la transcripción de las Memorias de los Protectores de Indígenas.

2 Para correspondencia, dirigirse a: Jorge Pavez Ojeda (jorge.pavez.ojeda@gmail.com). Universidad de Tarapacá, Investigador externo.

3 Para correspondencia, dirigirse a: Gertrudis Payàs Puigarnau (gpayas@uct.cl). Departamento de Lenguas y Núcleo de Estudios Interculturales e Interétnicos, Universidad Católica de Temuco.

4 Para correspondencia, dirigirse a: Fernando Ulloa Valenzuela (fernandoulloa@gmail. com). Investigador independiente. 
instituciones encargadas del proceso de radicación de los mapuches en comunidades (1894-1930), especialmente en el Protectorado de Indígenas, encargado de la defensa jurídica de los mapuches a los que la Comisión de Radicación "otorgaba" tierras por medio de los Títulos de Merced. El Protectorado de Indígenas llegó a tener cinco oficinas (en las provincias de Arauco, Malleco, Cautín, Valdivia y Llanquihue), y un sinnúmero de funcionarios como intérpretes, escribanos, ingenieros, mozos y los mismos abogados protectores. El Protectorado y la Comisión fueron los aparatos jurídicos estatales encargados de la aplicación de las leyes de radicación y procedimientos de reducción de los mapuche en comunidades, convirtiéndose por lo tanto en las instituciones más directamente vinculadas a las necesidades y demandas mapuche del periodo comprendido entre los años 1894 y 1930. En torno a estas instituciones, identificamos tres figuras de la mediación sociolingüística: los funcionarios públicos llamados "portero-intérpretes", los mapuches letrados que se desempeñan en forma independiente como "tinterillos", y los mapuche o mestizos que actualizan el desempeño de los antiguos "lenguaraces" de la frontera. Todos ellos se vincularon a los procesos jurídicos y administrativos gestionados por el Estado en el régimen tutelar de ocupación. Por eso estas instituciones nos parecen instancias clave para estudiar y entender las prácticas de contacto y mediación lingüísticas, el bilingüismo y la castellanización, la traducción y la interacción comunicativa, en un proceso tan difícil para la sociedad mapuche como el de la defensa de su derecho al territorio ante el avance de la colonización chilena y extranjera.

Palabras clave: sociolingüística histórica, mediación lingüística, traducción, contacto mapudungun-castellano, procesos de radicación.

\section{MAPUCHE INTERPRETERS AND THE PROTECTORADO DE INDIGENAS (1880-1930): LEGAL CONSTITUTION OF LAND PROPERTY, TRANSLATION AND CASTILIANIZATION OF NGULUMAPU}

\section{Abstract}

Based upon an extensive revision of archival sources as well as of the Annual Reports (Memorias) of Chile's Indian Protectorate (Protectorado de Indigenas), this paper proposes to study the mediators and socio-linguistic mediation practices employed by the institutions responsible for the settlement and relocation of the Mapuche people after their defeat under Chilean occupation forces (1894-1930). These institutions were the Protectorado -agency in charge of the legal defense of the Mapuche- and the Comisión de Radicación -which established the land to which a Mapuche family 
group could be entitled and drafted the entitlement (Titulo de Merced). The Protectorado had offices in five provinces south of the Biobío river (Arauco, Malleco, Cautín, Valdivia and Llanquihue), with a staff composed of interpreters, secretaries, engineers, assistants and the protectors themselves, usually lawyers. The Protectorado and the Comisión became the government's judiciary agencies applying the Indian settlement laws and procedures to force the Mapuche population to live in a system akin to reservations (comunidades). They were thus the agencies closest to the indigenous needs and demands during this period. Three characters were key to socio-linguistic mediation required by these agencies: the formal interpreters, officially called "portero-intérprete" as they acted also as janitors, the informal "tinterillos" (pettifoggers) of Mapuche origin, and the "lenguaraces", mediators of mixed origin, a version of the old frontier military interpreters. All of them had a role in the bureaucratic and judiciary processes administered by the State's tutelary regime of occupation. We intend to show that the study of these institutions can shed some light into the practices of linguistic contact, translation, communication and mediation, bilingualism and the eventual imposition of Spanish as the dominant language during the difficult period in which the Mapuche society strove to preserve the rights to their lands confronting the Chilean and foreign colonization.

Keywords: historical sociolinguistics, linguistic mediation, translation, mapudungun-spanish contact, native settlement in reservations.

Recibido: $16 / 01 / 20 \quad$ Aceptado: $17 / 03 / 20$

\section{INTRODUCCIÓN}

Este artículo se enmarca en una investigación mayor sobre el proceso de castellanización del Ngulumapu (Araucanía histórica), donde nos planteamos la pregunta por el rol que tuvieron las instituciones e instancias jurídicas involucradas en este proceso. Esta pregunta implica comprender las relaciones que se dieron entre el proceso jurídico de constitución de la propiedad de la tierra, en el llamado periodo "reduccional" (1880-1930) y el proceso de penetración de la lengua de ocupación, el castellano, en los territorios mapuches antes autónomos. En estos procesos, los intérpretes mapudungun-castellano, institucionalizados o no, aparecen como sujetos 
clave en tanto agentes de mediación no solo lingüística sino también jurídica, cultural, geográfica y política.

En este estudio, se volvió una fuente clave de información, la documentación producida por los Protectorados de Indígenas, que eran en el papel las instituciones estatales encargadas de la defensa jurídica de los mapuches, y, asimismo, la Comisión de Radicación, que era la institución encargada de asignar tierras declaradas fiscales a las familias mapuches y de cerciorarse en terreno del proceso. A partir del análisis de estas fuentes, proponemos reparar en las trayectorias familiares, educativas y laborales de los intérpretes contratados en los Protectorados y la Comisión Radicadora, análisis por el cual llegamos a identificar ciertos linajes que hicieron de la mediación socio-política y socio-lingüística una tradición familiar de varias generaciones que proveyeron de intérpretes bilingües al proceso de constitución de la propiedad, actuando también estos intérpretes como mediadores jurídico-administrativos, tanto en audiencias de oficina como en visitas a terreno de los Protectores de Indígenas. A partir de esta reconstrucción, problematizamos el impacto de las lógicas jurídicas de la constitución de la propiedad en la disposición y necesidad de los mapuches de adoptar/manejar el castellano como lengua de la dominación jurídica. Así resultó apreciable que la educación formal se volvió cada vez más solicitada por los mapuches, como creciente voluntad de alfabetización y adquisición del castellano, en un proceso que se inició tímidamente durante el periodo reduccional pero que se concretó masivamente en el periodo posterior, cuando ya había tenido lugar el proceso de radicación y el masivo despojo "legalizado" de tierras iniciado en el siglo XIX.

\section{EL PROTECTORADO DE INDÍGENAS Y LA COMISIÓN DE RADICACIÓN}

El Protectorado de Indígenas fue una institución jurídico-administrativa del Estado chileno, creada por la llamada Ley de Radicación de 1866. Su implementación práctica se inició recién en 1894, con el nombramiento del primer Protector de Indígenas de Cautín ${ }^{5}$, siendo disuelta la institución con la Ley para Indígenas promulgada en 1930. Como principio jurídico 
de protección de "naturales" se trata de la sobrevivencia en el derecho codificado nacional de un principio del Derecho Indiano, y sus bases jurídicas se pueden incluso remontar a los principios proteccionistas establecidos por el Derecho Romano. (Bayle 1945, Bonnet 1992, Cuena 1998, De la Torre 2010, Cunill 2012 y 2019)

La institución chilena del Protectorado de Indígenas viene establecida en la primera de las llamadas Leyes de Radicación, en específico, la Ley del 4 de diciembre de 1866, que dispone en su artículo 8: "En los territorios fronterizos de indígenas, habrá un letrado con el título de Protector de Indígenas, el cual ejercerá las funciones que atribuye al Intendente y Gobernadores el decreto de 14 de marzo de 1853, y representará los derechos de los indígenas en todas las circunstancias que se ofrezcan, y especialmente en el deslinde de sus posesiones y en todos los contratos traslaticios de dominio". Esta misma Ley de 1866 permitía la fundación de poblaciones en los territorios indígenas, y prohibió la enajenación de terrenos entre particulares, salvo que estuvieran inscritos y registrados. La ley también creó la Comisión de Radicación de Indígenas, encargada de efectuar los deslindes de los terrenos que serían entregados a los mapuche por medio de un Título de Merced $^{6}$.

Los "territorios fronterizos de indígenas" habían sido definidos en el artículo 3 de la Ley del 7 de diciembre de 1852, como: "El territorio comprendido entre el Bío-Bío y el Toltén y entre los Andes y la cordillera de la costa. Será regido como territorio fronterizo. Lo mismo se observará con el comprendido entre Carampangue y el Toltén, la cordillera de la costa y el mar"; conocidas también como Alta y Baja Frontera. Solo en 1906, dicha condición se hará extensiva a las provincias de Valdivia y de Llanquihue, con la consiguiente definición de funciones establecidas en el decreto de 1853, que se trasladan por Ley de 1866 al Protector de Indígenas.

Una segunda Ley de Radicación, del 4 de agosto de 1874, en su artículo 10, confiere al Protector de Indígenas las representaciones de los intereses fiscales y la facultad de "litigar como pobre" en defensa de los indígenas.

6 La misma ley establecía la forma de definir las tierras indígenas. Se les entregarían títulos a los que demostraran ocupación efectiva y continuada; si varios indígenas pretendieren un terreno, se favorecería al que lo hubiera ocupado en los últimos cinco años; si varios indígenas poseyeren un mismo terreno, se les consideraría comuneros y se les dividiría en partes iguales; todos los derechos de propiedad se le reconocerían al cabeza de familia (varón o mujer); si los indígenas poseyeran un terreno como reducción dependiente de un cacique, se les daría la propiedad en común; si una octava parte de los jefes de familia de una reducción quisieren que se les otorgase la propiedad por separado, se haría la división, dando al cacique el triple de terreno que se les asignase a los cabezas de familia; y se preferirían los límites naturales para deslindar las propiedades. (Almonacid 2009: 9) 
Esa misma ley prohíbe la adquisición de tierras por particulares en el territorio comprendido entre el río Malleco y el límite norte de la provincia de Valdivia, cuestión que en la práctica ya había ocurrido y de allí las pugnas futuras. Un año después, la Ley del 15 de octubre de 1875 suprimió el cargo de Protector, probablemente debido a que el territorio fronterizo se había vuelto un espacio controlado por fuerza militar que no quería tener que rendir cuenta a agentes civiles. El cargo fue restablecido en el artículo 3 de la Ley del 20 de enero de 1883, es decir poco tiempo después de la ocupación de Temuco (la Línea del Cautín de 1881) y a solo días de la refundación de Villarrica por el Ejército chileno. Una década más tarde, por Ley del 11 de enero de 1893, se extendió la prohibición de adquisición de tierras desde la provincia de Valdivia al sur.

Mientras tanto, en lo relativo a Arauco, recién en 1884 se empezó a hacer efectiva la Ley de 1866, creándose la Comisión de Radicación, y como aún no se designaban los Protectores de Indígenas para los "territorios fronterizos", un decreto del 10 de noviembre de 1884 asignó a los Promotores Fiscales la defensa y representación de los indígenas "en los litigios sobre propiedad o posesión de sus tierras" y los contratos de compra-venta que celebrasen. (Jara 1956)

A los dos años de funcionamiento efectivo del Protectorado de Cautín, el Reglamento de la Inspección General de Tierras y Colonización (1896) menciona el cargo de "Intérprete del Protectorado", quien "tendrá las obligaciones que señale el protector de indígenas i prestará también sus servicios ante la Comisión Radicadora" (Jara 1956: 61). Recordemos que la Comisión, en la práctica, había iniciado su operación doce años antes. Los problemas de comunicación que se fueron planteando en los primeros años del proceso de radicación parecen haber llevado a las autoridades a incluir al intérprete institucionalizado como funcionario indispensable para la eficacia de las labores de la Comisión y el Protectorado.

Si en la norma la descripción de las obligaciones del intérprete es, a la vez, insustancial e ilustrativa de lo que el cargo implicaba, en las Memorias anuales de los Protectores se registran más detalles sobre las interacciones jurídicas en las que participa como mediador socio-lingüístico: no basta con traducir palabras, se trata más bien de dar a entender el trasfondo de una norma o de la toma de una decisión y los marcos jurídicos y culturales en los que se asienta cada medida.

Los informes de principios del siglo XX no coinciden en cuanto a la demografía mapuche; mientras el Protector Eulogio Robles la evalúa en 70.000 individuos (Robles 1902: 194), el Censo practicado en 1906 establece la existencia de 101.000 mapuches (Censo 1907). Además, se percibe un gran desconocimiento respecto a la situación sociolingüística en el territorio, 
resulta incierta la penetración del castellano y poco se sabe de la vigencia del bilingüismo. Cabe además resaltar que una cosa son los usos del argot jurídico y otra, la capacidad de expresión y comprensión del/en castellano. El protector Robles, por ejemplo, señala en 1905 que "tres cuartas partes [de los indígenas] hablan español", pero dos años después, en 1907, baja su estimación a un 40\% (Robles 1905: 190; 1907: 80), lo que demuestra la irregular percepción que se tenía de los usos lingüísticos y también que las dificultades de comunicación se fueron imponiendo como evidencia a partir de la práctica misma de las tareas del Protectorado.

La existencia de zonas con mayor o menor presencia de escuelas misionales, la posibilidad de provenir de familias que habían adoptado el bilingüismo con anterioridad a la Ocupación por diversos factores, la existencia de chiñurras o mujeres de origen chileno al interior de las familias mapuches haciendo del castellano lengua materna, la vinculación diaria con lenguaraces ya sea para la política de parlamentos (trawün, koyagtun) o para el comercio e intercambio, la lejanía o cercanía de centros urbanos o militares, rutas comerciales o cruces de río, que invitaran a un manejo "champurriado" (mezclado, híbrido) del castellano, son factores socioantropológicos importantes para ponderar la penetración del castellano en algunos sectores mapuches. Además, en términos sociolingüísticos, la diferencia entre entender lo que se le hablaba en castellano y hacerse entender en esa lengua por parte de los mapuches no debió ser inmediatamente obvia para los funcionarios. Tampoco era fácil dar cuenta a las autoridades que el castellano que sabían los indígenas era solo suficiente para situaciones de habla corriente, pero que en instancias especializadas era necesaria la asistencia de un intérprete. Y menos claro aún debió ser la determinación de la desventaja social y política sobre la capacidad de comunicación y de comprensión lingüística de los mapuches en situaciones como las audiencias con Protectores o Comisionados.

\section{LAS MEMORIAS DE LOS PROTECTORES DE INDÍGENAS Y LA TRADUCCIÓN EN AUDIENCIAS}

Es apreciable que al momento de la instalación de la figura del intérprete, el mediador asignado para desempeñar tal función al alero de una institución; como sujeto bilingüe debía interpretar (oralmente y casi en simultáneo), pero además debía estar a disposición de sus superiores para cualquier otra tarea que se le indicara. La mediación lingüística per se no se percibió en 
un principio como una necesidad singular sino que formaba parte de un conjunto de actividades de servicio, cosa, por demás, comprensible en vista de que las dificultades de comunicación que se había de enfrentar no eran solo debidas a la incomprensión lingüística.

Una lectura atenta de las Memorias pone en evidencia no solo el carácter bilingüe de la mayor parte de las interacciones de "oficina" y en el terreno, sino también las diferencias de entendimiento y múltiples equívocos, dados por el choque cultural y social. Una audiencia era propiamente un espacio tensionado por las atribuciones que se arrogaba el funcionario a cargo y por el reconocimiento/rechazo de los mapuches hacia la institucionalidad chilena. Aun cuando el Protector era en rigor el responsable de aconsejar, proteger y acoger las reclamaciones con la finalidad de evitar abusos (por eso se le tenía por "tutor legal" del mapuche considerado bajo el principio jurídico de "menor" o "miserable"), vemos que no siempre fue fluida la comunicación. El diálogo de la audiencia con Juan Epulef, que reproduce el protector Carlos Iribarra en su Memoria del año 1907, es un ejemplo notable de incomprensión mutua de las partes, incluso con "un indio que posee el español". En este intercambio, realizado sin la mediación de un intérprete, se percibe que las dificultades de comunicación no afectan solamente la pertinencia y transmisión eficaz de la información, sino que también generan toda una serie de asperezas en el diálogo y recriminaciones de quien se siente en posición de autoridad para definir el marco y las dinámicas comunicativas que impone a un reclamante mapuche infantilizado por este tutor legal:

¿Cómo te llamas?-José.—¿Tu apellido?-Epulef.—¿Tienes padre?Si.—¿Cómo se llama?—José Antillanca.—Entónces, ¿cómo dijiste que eras Epulef?-Mi madre se llama Rosario Epulef.—¿De modo que llevas el apellido de tu madre en lugar del de tu padre? - Me dicen todos Epulef.-Tu padre, ¿es casado con tu madre?-Sí, a la usanza.-¿Por qué no vino tu padre?-Se fué para la Arjentina.—¿De dónde eres? De Loncoche.- ¿Vives en ese pueblo? - No.—Dime donde.-Con mi madre, tres hermanos i...-Te pregunto simplemente si vives en Loncoche o en el campo.- Vivo en la posesion de mi padre que está en...-¿Cómo se llama ese terreno?-Pelepuye.—¿Hai mas indíjenas ahí?—Maipúe tiene naturales por dos lados, pero no son de mi familia.-iQué es eso Maipúe?-Bah, esa es la posesion donde vivo.-Pero si acabas de decir que vives en Pelepuye.-Es todo un mismo paño, todo se llama Pelepuye.-_De manera que Maipúe está dentro de los límites de Pelepuye? - Cómo no, pué'; Maipúe se llama el pedazo de mi padre.¿Desde cuándo vives alli? — No tengo recuerdo.- ¿Hará mas de un año?-Yo nací en Maipúe.—Bueno, ¿a qué vienes, qué deseas? —Como me dijeron que el señor Gobierno habia mandado a su señorío pa' defender 
a la indíjena i que...-Dime luego, ¿a qué vienes?_-Le están quitando la posesion a mi madre.__Quiénes?-Mi madre no pudo venir porque es mui vieja i como...-No me cuentes lo que no te pregunto, responde quien le quita terreno a tu madre.-El aleman.—_Cómo se llama?-—Donde sé decir el apelativo, cuando es tan rudo; le dicen el aleman rico._- ¿Tampoco sabes el nombre? - Parece que algunos lo mientan Manuel, creo que Albran. - Voi a preguntar a un natural (sale a la portería i vuelve con el dato qué recoje entre los que esperan audiencia).—¿Dónde vive ese aleman?-En su fundo que está ahí mesmo.-¿Cómo ahí mismo, está vecino?-Cerca, pué._¿Habrá una cuadra de Maipúe?-Creo que sí.—¿Habrán veinte cuadras?_—Eso debe ser!—_Pero sabrás el nombre del fundo del aleman?-Es Lliu. - Cuentame que es lo que ha hecho este aleman.- Hizo tira una voltiá i vino a poner varones cerca de la casa de nosotros; yo he sacado dos veces esos varones, pero ayer me agarró a guascasos i puso un cuidador.-¿Cuanto tiempo que hizo ese cerco? - Cuantuá.—¿Hará un año?-Despues que mi taita se fué pa lotro lao._¿Cuando se fué tu padre para la Arjentina? - Hace tiempo ya.-Yo necesito saber si hace mas de un año o hace ménos desde que el aleman entró en la posesion de ustedes.-Fué después de la cosecha.-Ahora me vas a decir los deslindes de Maipúe; fíjate bien en este papel (se dibuja un pequeño cróquis con los puntos cardinales).-Oye, ¿quien vive al Norte?-El aleman.—_Al Sur?_Al Sur... Al Sur... Espérese... Espérese. Al Sur están los colonos, pué.-¿Al Este, es decir, a la derecha.-Los Huenchules. - Dime el nombre del que hace cabeza entre los Huenchules.-Antonio.-_Al Oeste, o izquierda?-A la izquierda están los naturales;-_Nómbramelos.-Juan, José Maria, Pedro...-Basta; nómbrame ahora seis personas que puedan venir a declarar al juzgado como que es verdad que el aleman, cuyo nombre te dijeron era... ha usurpado o entrado en la posesion de ustedes, construido un cerco i colocado un cuidador: i que sepan ademas que este aleman nunca ha poseido en Maipúe sino en Lliu i que ustedes han poseido mas de un año, tranquilamente i sin interrupcion.-_Qué su señorio! Si este aleman no nos deja tranquilos desde hace mucho tiempo.-Dame los nombres que te pido.- - Traeré a mi tío Pedro.- - No sirven tus parientes.-Bueno, traeré a Nicolas Loncon._-Otro._-Juan Aucal. -Otro._- José Segundo.—¿I el apellido de éste?-Le dicen Chindo.- Continúa nombrando otros.Casi todos los Quilla saben que el terreno es de mi madre.-Yo necesito me nombres tres mas, a lo ménos.-_Qué no sirven los que le nombré ya?-Son pocos dos-Pero si le dije tres.-José Segundo no sirve, nombra otros.- ¿Por qué nó?-Ya te he dicho que nombres otros.Clemente Coipayante.-Otro.- Juan Epuyao. Otro.-No sé ninguno mas.- ¿Todos los que nombraste trabajan en el campo?-Sí.-Te quiero decir si son agricultores._¿Dónde viven estos testigos?-En el campo.-Loncon, ¿dónde vive?-En Futa-Mupu.—¿Aucal?-En 
Padagua.- ¿I los otros?-En Pelepuye todos. - Fíjate mucho en lo que te voi a encargar.-Bueno, señorío. - Irás, desde el martes adelante a saber todos los dias a donde el Juez de Subdelegacion, a preguntarle el dia que notificará al aleman i, cuando lo notifique traerás, a Valdivia tus testigos que has nombrado de modo que están aquí en la mañana del quinto dia despues de la notificacion. Mejor seria que llegaran un dia antes.-Aucal no va a querer venir-__Por qué?-Se está muriendo de enfermedad.-Trae los demas.-Mire su señorío, ¿por qué no me da una órden mejor pa romper el cerco al aleman?-No se puede, véte i no olvides lo que te he dicho. (Irribarra 1908: 239-241)

Este diálogo grafica también toda la serie de problemas que se presentaron al momento de judicializar la defensa de las tierras de los mapuches, en la medida en que sus formas de ocupación, uso, demarcación, propiedad y herencia de la tierra no correspondían a los cánones del derecho occidental. Es a todo esto que hay que sumar el problema de la traducción estrictamente lingüística, considerando que la mayoría de la población mapuche no hablaba castellano. En este contexto, la actuación del intérprete bilingüe podía incluso contribuir a allanar estas diferencias y equívocos, haciendo las veces de "explicador" a las partes dialogantes. Esta actividad de mediación "técnica" (jurídica, geográfica, sociológica) probablemente más común de lo que los documentos expresan, sumada a la mediación lingüística, debía comenzar desde el ingreso del indígena a la oficina del Protectorado, y prolongarse durante toda la audiencia, con toda suerte de interrupciones por la gran cantidad de reclamos que se atendían diariamente. A pesar del carácter ancilar (subordinado) de sus funciones, el cargo de "portero-intérprete" se volvió así de absoluta necesidad, y repetidamente las memorias dan cuenta de quejas por la falta de estos individuos o lo enjuto de sus remuneraciones. Estas tensiones y contradicciones fueron también vividas por los propios intérpretes que, formando parte de la sociedad indígena, operaban como agentes del Estado. Si bien sus voces no son audibles en las Memorias, sus ausencias, renuncias, las quejas de los Protectores y el poco reconocimiento oficial de su labor expresan bien el hecho de que el cargo, aunque daba prestigio, no generaba toda la proyección laboral o estabilidad profesional/ material, deseable para los mapuches ${ }^{7}$.

Ha sido hasta la actualidad muy irregular la valoración del factor lingüístico en la administración de justicia y otras instancias del Estado, en países plurilingües. La profesionalización del oficio, cuando la hay, es muy reciente, y la relación entre Derechos Lingüísticos y Derechos Humanos todavía no es un hecho reconocido en todas partes. $C f$. para el caso chileno actual; Delgado y Curihuinca (2012) y Le Bonniec y Nahuelcheo (2017). 
Esto, porque, a pesar de su importancia como condición básica de realización de la tarea de protección jurídica de los mapuche y sus tierras, la función de "portero-intérprete" del Protectorado ocupaba el último escalafón de remuneraciones en la administración (entre 1907 y 1912 varía de 600 a 820 pesos anuales), bien por debajo de los agentes judiciales y escribientes (1.200 pesos). No solo los sueldos eran comparativamente bajos, afectando la posibilidad de retener a los buenos intérpretes o conseguir sus reemplazos; tampoco se tramitaban diligentemente esos reemplazos, de manera que los reemplazantes no recibían sus sueldos y los Protectores tenían que adelantar esos pagos de sus propios bolsillos.

Cuadro 1: Partida Presupuestaria Inspección General de Colonización e Inmigración (1910); Memorias del Protectorado de Arauco y de Malleco (Labbé 1911; Oñate 1911).

\begin{tabular}{|l|c|c|c|}
\hline Cargo & $\begin{array}{c}\text { Asignación } \\
\text { anual } \\
\text { Presupuesto } \\
\text { nacional }\end{array}$ & $\begin{array}{c}\text { Propuesta } \\
\text { Protector } \\
\text { de Arauco }\end{array}$ & $\begin{array}{c}\text { Propuesta } \\
\text { Protector } \\
\text { de Malleco }\end{array}$ \\
\hline $\begin{array}{l}\text { Juez Letrado de capital de } \\
\text { Provincia (referencia) }\end{array}$ & 12.000 & & \\
\hline $\begin{array}{l}\text { Inspector General de } \\
\text { Colonización e Inmigración }\end{array}$ & 12.000 & & \\
\hline Secretario de Colonización & 6.000 & & \\
\hline Archivero IGCI & 1.200 & & 10.000 \\
\hline Portero IGCI & 840 & & 7.000 \\
\hline Protector de Indígenas & 3.500 & 10.000 & 3.600 \\
\hline $\begin{array}{l}\text { Asignación para } \\
\text { casa de Protector }\end{array}$ & 3.000 & & \\
\hline Ingeniero de Protectorado & 4.000 & 6.000 & 2.400 \\
\hline $\begin{array}{l}\text { Agente judicial } \\
\text { del Protectorado } \\
\text { (Malleco y Cautín) }\end{array}$ & 2.400 & 3.600 & 1.500 \\
\hline $\begin{array}{l}\text { Escribiente del protectorado } \\
1.800 \text { (Malleco } \\
\text { y Cautín)/ } \\
1.200 \text { (Otros) }\end{array}$ & 1.800 & \\
\hline $\begin{array}{l}\text { Intérprete portero } \\
\text { del protectorado }\end{array}$ & 720 & 1.200 & \\
\hline
\end{tabular}


La importancia, recurrencia e intensidad del trabajo de mediación realizado por los porteros-intérpretes, pueden dimensionarse a partir de las audiencias presenciales otorgadas por los Protectores a los solicitantes y reclamantes mapuche. ¿Quién recibía a los recién llegados? ¿Quién explicaba los términos en los que operaba la institucionalidad, sus plazos y los modos? ¿Quién hacia inteligible los formalismos jurídicos? Recordemos que los Protectores no solían hablar mapudungun, y que la mayoría de los mapuche no hablaba castellano, lo que hacía menos probable el manejo de conceptos jurídicos occidentales, de ahí que los intérpretes fueran figuras clave en estas audiencias, sobre las cuales los Protectores son bastante precisos en sus Memorias. Por ejemplo, el Protector de Valdivia señala en 1907 que: "hay meses, de Setiembre a Enero inclusives, en que se oyen hasta diez i quince reclamos [...] por día [...] en que cada reclamante ocupa, como término medio, treinta minutos de la audiencia diaria. Muchísimos absorben hasta una hora y media" (Irribarra 1908: 241). Esto resulta en un rango entre cinco y quince horas de audiencia bilingüe por día. Las audiencias son también intensas ya que es necesario traducir a varios participantes, como recuerda el mismo Irribarra: "Durante el año de 1908 esta oficina ha oído 407 reclamos que significan audiencias para mas de 500 personas, por cuanto a un solo reclamo concurren a veces hasta $3 \mathrm{y}$ mas individuos". (Irribarra 1909: 359).

Respecto a las audiencias, lo extenso de la jurisdicción, la gran variedad de problemas que se abordan, el amplio papel del Protector y las dificultades de entendimiento encontradas, el Protector de Cautín en 1913, Eleazar Bravo, comenta que:

A estas atenciones he dedicado hasta hoy tres a cuatro horas diarias. Generalmente, todos los indígenas acuden al Protector en todos sus actos de alguna importancia: los divorciados, los que desean construir una casa, casarse con arreglo a la ley, ausentarse a la Argentina, hacer un cierro; en fin, hasta recoger el producto de un manzano. El Protector de Cautín es de hecho juez, parte, abogado, consejero, comisionista, depositario, gestor administrativo, en una palabra, tiene por clientela 40.000 indígenas difíciles de entender, y a cuya Oficina acuden diariamente 80 a 100 a quienes en una audiencia o dos podría arreglar definitivamente si tuviera atribuciones para ello. Las consultas son numerosas y aumentan a diario, a medida que van adquiriendo el conocimiento de que el infrascrito los sirve en buena forma y cuando no le es posible atender sus asuntos judiciales, les recomienda defensores honrados a quienes, si no puedo dirigir, al menos fiscalizo, aunque sea de lejos". (Bravo 1914: 119-120) 
Entre 1907 y 1913, varios Protectores cuantifican su trabajo en relación con los reclamos mapuche recibidos en audiencias y los comparendos efectuados. Todas estas atenciones requerían de la presencia activa del "portero-intérprete", por lo que las sistematizamos en el siguiente cuadro:

Cuadro 2: Reclamos y comparendos en audiencias otorgadas a solicitantes mapuche en los Protectorados de Malleco, Llanquihue, Valdivia y Arauco (1910-1914). Fuente: Memorias de los Protectores de Indígenas (Oñate 1911; Arrieta 1912; Cerda 1911; Arrieta 1914; Muñoz 1914).

\begin{tabular}{|l|c|c|c|c|c|c|}
\hline Audiencias & $\begin{array}{c}\text { Malleco } \\
\mathbf{1 9 1 0}\end{array}$ & $\begin{array}{c}\text { Malleco } \\
\mathbf{1 9 1 1}\end{array}$ & $\begin{array}{c}\text { Llanquihue } \\
\mathbf{1 9 1 1}\end{array}$ & $\begin{array}{c}\text { Valdivia } \\
\mathbf{1 9 1 3}\end{array}$ & $\begin{array}{c}\text { Malleco } \\
\mathbf{1 9 1 3}\end{array}$ & $\begin{array}{c}\text { Arauco } \\
\mathbf{1 9 1 4}\end{array}$ \\
\hline Reclamos & 316 & 415 & 423 & 425 & 463 & 233 \\
\hline Comparendos & 21 & 42 & 67 & - & 3 & - \\
\hline
\end{tabular}

Como recuerda el protector Irribarra, al menos un tercio de estos reclamos se materializan en demandas judiciales, y la mitad de estas exige la elaboración de documentos dirigidos a la Inspección de Colonización, la Comisión Radicadora, los jueces letrados y las Cortes (Irribarra 1908 y 1914). El protector Muñoz, por su parte, da un detalle del contenido de los 233 reclamos que atendió en Arauco, de los cuales 120 piden "separadamente se les entregue los pedazos de suelo que les corresponde según los Títulos de Merced"; otros 50 son "en contra de caciques i caciquillos que ocupan mayor estension de terrenos que lo que les corresponde llevando a las hijuelas jente estraña a las reducciones como arrendatarios o medieros"; unos 10, "Por infracción a la lei de Reclutas i Reemplazos"; 20, "Pidiendo radicación i se les conceda Título de Merced 20"; y finalmente 53, "por otras causas que seria mui largo detallar”. (Muñoz 1914: 105)

\section{SOCIOGRAFÍA DE LOS INTÉRPRETES MAPUCHES}

La figura del "portero-intérprete", la importancia política de la traducción y la intensidad de su trabajo de mediación, entroncan con el rol que desempeñaron en los siglos precedentes los antiguos lenguas o lenguaraces en los parlamentos, y los antiguos "capitanes de indios amigos" en las distintas parcialidades donde operaban en el periodo colonial y también en el siglo XIX republicano. 
En el periodo aquí estudiado, la necesidad de una mediación se acrecentará porque ya no serán solo los lonkos o cabezas principales quienes tendrán que interactuar con la institucionalidad chilena, sino más bien la generalidad de los mapuches afectados por el proceso de Radicación. En este ámbito fundamentalmente judicial y administrativo, los misioneros que antiguamente se involucraban en las interacciones políticas y en las negociaciones de paz, quedaban en una posición más lejana, más bien como espectadores y testigos que como intervinientes directos. Se abrió así un espacio que hubo que ocupar y los mapuches que ya tenían nociones del castellano quedaron en una posición relativamente ventajosa para desempeñarse en los roles de portero-intérprete, ya que al privilegiarse la castellanización no existieron escuelas que formaran a funcionarios chilenos en el mapudungun.

Para comprender la adopción temprana del bilingüismo por algunas renombradas familias mapuches, es necesario remontarse en primer lugar al sistema colonial de los "caciques gobernadores" indígenas, cuya lealtad a la Corona hispana estaba asociada al pago de un sueldo y a la entrega de "bastones de mando", institución de alianzas que se prolonga en el periodo republicano (Guarda 1968, León 1999, Foerster y Villarroel 2008). A estas figuras hay que agregar las de los "caciques embajadores" instalados en Santiago en el siglo XVIII (Zavala 2008), y las embajadas o viajes a la capital que seguirán practicándose en el siglo XIX y XX. Todo ello va haciendo patente la importancia del manejo del idioma castellano por las jefaturas mapuche, con el fin de facilitar el entendimiento y la comunicación con la sociedad hispano-criolla, y especialmente por las sospechas y aprensiones que pesaban sobre el actuar y los intereses de misioneros, capitanes de amigos y lenguaraces. Adicionalmente, a las funciones de mediación lingüística oral instaladas en torno a las jefaturas, se agregarán en el siglo XVIII y XIX las de mediación escritural, dando forma a los archivos y secretarías indígenas en lo que hemos llamado el "malal letrado". (Pavez 2008; cf. tb. Vezub 2009, Vezub y De Jong 2019)

La primera parte del siglo XIX está marcada por las batallas de las guerras de Independencia y la posterior Guerra a Muerte, donde las jefaturas mapuches que se aliaron primero con la República destacaron en el manejo del castellano. Entre estos grupos se encuentran los costinos o lafkenche del cacique Porma, los cholcholinos de Coñoepan, los abajinos o nagche de Kolipi y sus parientes Koliman, y en cierta medida los angolinos de Dumulevi. Tempranamente, por su posición más cercana a la frontera y la función de contención y bisagra que esto implicaba, costinos y abajinos (de las actuales provincias de Arauco y Malleco) fueron sometidos a la presión para abandonar sus tierras, lo que llevó a sus liderazgos a sostener mayor 
interacción con las autoridades chilenas y constatar la necesidad de tener allegados que tuvieran conocimiento del castellano.

En la segunda mitad del siglo, los institucionalizados capitanes de amigos y otros mediadores informales como los lenguaraces, fueron progresivamente generando desconfianza en las autoridades de la república, algo que ya había ocurrido en el periodo conocido como "La Patria Vieja" de la Independencia. Aunque a comienzos de siglo la pervivencia de estos mediadores estuvo en duda, desde el Parlamento de Tapihue de 1825 se los asumió como una carga inevitable para el Estado (Ulloa 2009). Hacia 1852, con posterioridad a la creación de la Provincia de Arauco, cuando varios de estos funcionarios se mostraron más próximos a la estrategia política de resistencia desplegada por los arribanos y llanistas encabezados por Mañil Wenü, varios fueron perseguidos y progresivamente reemplazados en sus funciones por sujetos de mayor confianza: los hijos de los lonkos más cercanos a la República, especialmente en la provincia de Malleco y en las proximidades de las ciudades como Temuco fundadas hacia fines de siglo. Esto implicó que los mediadores cercanos a los arribanos o wenteche perdieran la confianza de los militares y agentes estatales fronterizos, mientras que los abajinos, más cercanos a la posición asimilacionista, comenzaron a confiar las tareas de traducción a sus propios descendientes, cosa que el Estado respaldó, siendo algunos de ellos recibidos como ahijados de los oficiales militares de la ocupación como Cornelio Saavedra o Gregorio Urrutia, y educados en las misiones o colegios de Nacimiento, Los Ángeles, Chillán o Santiago. (Guevara 1913, Pavez 2008, Ulloa 2020)

La trayectoria de las familias de lonkos y ulmenes lleva a pensar que no todos los mapuche de las cinco provincias cubiertas por los Protectorados (1909-1916) tuvieron la misma capacidad de relacionarse con las instituciones del Estado en términos lingüísticos y jurídicos. En estas familias, miembros de varias generaciones habían adquirido el idioma castellano, y los lonkos eran más proclives a la educación formal de sus hijos en escuelas públicas o misionales, transformándose los pupilos, tras los años de instrucción, en asistentes de sus padres y en tomadores de decisiones, en cuestiones políticas primero y jurídico-administrativas después. De ambos tipos de familias, provinieron muchos intérpretes bilingües y también muchos dirigentes de las organizaciones mapuches de la primera mitad del siglo XX como la Sociedad Caupolicán, la Federación Araucana o la Unión Araucana. Las familias Melin de Purén, Coñuepan de Cholchol, Painemal de Cholchol, Urrutia de Temuco, los Melivilu y Painevilo de Maquehue, Manquilef de Metrenco, Chihuailaf de Cunco, Neculman de Boroa, Paillalef de Freire, Aburto de Loncoche, Millanao de Villarrica, y varias decenas más, constituyeron tempranamente una élite letrada del pueblo mapuche. (Guevara 1913, Robles 1940, Foerster y Montecino 1988, Menard y Pavez 2007, Pavez 2008 y 2015) 
El surgimiento y consolidación de esta élite bilingüe de hijos de lonkos durante el periodo reduccional se puede explicar también en términos económicos. Al respecto, Jorge Pinto distingue tres "grupos económicos" mapuche en el periodo reduccional: los "campesinos pobres", los "profesionales" y los "empresarios". Mientras que una parte de los dirigentes citados más arriba se pueden contar, al igual que los intérpretes, dentro del grupo de profesionales, otros como Catrileo o Coñuepan, son reconocidos empresarios. En 1905, el Anuario Comercial de Cautín identifica siete nombres mapuche entre los 300 grandes propietarios de la región: Antonio Neculman, la Sucesión Huenchecan, Ignacio Levicura, Cacique Huaiquil, Cacique Huileman, Antonio Nahuelcura, y Domingo Marivil (Pinto 2014: 113). Este grupo de "empresarios" mapuche, al igual que el de los profesionales puede considerarse dentro de la minoría mapuche que practicaba el bilingüismo y eran considerados "araucanos civilizados", pero la gran masa de "campesinos pobres" era aún monolingüe en mapudungun, monolingüismo que se volvía más común al alejarse de las ciudades. La élite mapuche letrada tendrá mayor facilidad para relacionarse con las instituciones reduccionales como el Protectorado de Indígenas, la Comisión Radicadora, la Inspección General y el Ministerio de Colonización, y también prolongará la antigua práctica de viajar a Santiago a solicitar audiencias con el Presidente de la República y sus ministros (Pavez 2008). Mientras que la gran mayoría de mapuches necesita intérpretes y agentes para-judiciales ("tinterillos") para transmitir sus demandas, algunos jefes de reducciones tendrán la capacidad de escribir y firmar sus reclamos, por ellos mismos o apoyados por otros mapuches letrados, evidenciando así la penetración de las "prácticas letradas" en castellano en ciertos sectores de la sociedad mapuche.

Este no es el caso del grupo mayoritario de los "campesinos pobres" mapuche, que es el grupo al cual parece referir un informe solicitado por el protector Robles al juez Juan Parga de la Corte de Apelaciones de Concepción, donde el magistrado expresa que "con motivo de una visita extraordinaria practicada en el juzgado de Temuco":

No me seria posible dar a V. S. Iltma, una idea exacta de las condiciones deplorables en que se encuentran los indijenas en lo que se relaciona con la administracion de justicia, i lo que es peor todavia, el réjimen actual creado por nuestras leyes i disposiciones administrativas, no ofrece medios de cambiar esa situación [...] i porque el indíjena no entiende la jerga judicial de los tiempos de don Alfonso el Sabio i no comprende qué cosas son autos de estrados, emplazamientos, rebeldías i contumacias, no conociendo el español, se pronuncia en su contra una sentencia con todos los requisitos que enseña el formulario, la cual sentencia lo condena, según los casos, ora a entregar sus bienes, ora a presidio i a sufrir azotes 
o a muerte sin defensa cierta i positiva. Esto seria un sarcasmo si no entrañara una evidente iniquidad. (Robles 1902: 36-37)

\title{
5. LOS INTÉRPRETES DEL PROTECTORADO Y LA COMISIÓN RADICADORA
}

\begin{abstract}
Una lectura "indicial" (Ginzburg 2008) y "a contrapelo" (Comaroff y Comaroff 1992) de la documentación de archivo nos ha permitido reconstruir algunas trayectorias de los intérpretes que actúan en las instituciones de la radicación, especialmente de los Protectorados de Cautín y de Valdivia, que son los más profusos en indicaciones sobre sus "porteros-intérpretes". Además, estos Protectorados se caracterizan por haber sido liderados por los Protectores más duraderos en su cargo: Eulogio Robles Rodríguez y Armando Moraga en Cautín, quienes ocuparon el cargo desde 1900 a 1912 y 1918 a 1927 respectivamente, y Carlos Irribarra en Valdivia, quien ocupa el cargo durante toda la existencia de ese Protectorado (1907-1923).
\end{abstract}

\section{Protectorado de Indígenas de Cautín}

El protector Eulogio Robles Rodríguez fue uno de los abogados más importantes en ocupar el cargo de Protector de Cautín, donde se dedicó no solo a la acción jurídica sino también a la etnografía del pueblo mapuche, y desarrolló múltiples y profundas relaciones con sus representantes políticos, religiosos y lingüísticos. Durante sus doce años en el cargo, interactuó con miles de mapuches y los defendió en cientos de juicios para la restitución de sus tierras. Su carrera llegará hasta la Corte Suprema, y en tanto miembro de ella, visitó el XVIII Congreso Araucano de diciembre de 1938, después de muchos años alejado del Ngulumapu (Aburto 1938: 308). En los textos oficiales y personales de Robles, se encuentran diversos indicios sobre su trabajo con intérpretes mapuche y mestizos.

Manuel Morales se había iniciado como intérprete en el Juzgado de Temuco en $1888^{8}$ y es probablemente en ese juzgado donde conoció al 
protector Eulogio Robles cuando este último oficiaba de juez letrado. En marzo de 1902, Morales reemplaza a Juan Bautista Urrutia Loncon por licencia médica. Al mes de julio aún no se le ha pagado sueldo y el Protector ni siquiera ha obtenido respuesta respecto a su contratación ${ }^{9}$. Urrutia Loncon volverá a ocupar su cargo de portero-intérprete en el Protectorado de Cautín, donde permanecerá al parecer hasta 1906. En 1910, en una carta a Rodolfo Lenz, el protector Robles tiene elogiosas palabras para el joven intérprete mapuche: "Sentí mucho la pérdida del antiguo [intérprete], un joven Urrutia Loncon, que tenia sed de aprender y que después de fatigarse todo el día en la Oficina, se hacia el tiempo para asistir a una escuela nocturna. Encontró poco el sueldo y yo pude, después de algunas peleas con la Comisión Radicadora, conseguir se le diera una buena hijuela y hoy trabaja en el campo con éxito" 10 .

Antes de la escuela nocturna de Temuco, Urrutia se había formado en la Misión Araucana de Quepe, y cuando trabajó con Robles, lo apoyó en tareas etnográficas como traductor pero también como secretario, al registrar los cantos chamánicos en la visita a un machitún, documentado por el mismo Protector en 1907 (Robles 1940). El retiro de Urrutia al campo durará algunos años, sin embargo, en 1913 aparece nuevamente contratado como porterointérprete en el Protectorado de Cautín, y en 1917 pasa al cargo de escribiente en el mismo Protectorado, bajo la dirección del protector Francisco Mozó ${ }^{11}$.

$\mathrm{Al}$ igual que Morales, el intérprete José Manuel Huento se había iniciado en la función pública como intérprete del Juzgado de Letras de Temuco, donde aparece registrado al menos desde $1889^{12}$. Hijo del cacique antiguo Antonio Huento de Temuco, Huento entra al Protectorado de Cautín en 1906, donde trabajará como portero-intérprete hasta al menos 1910. Sobre él escribe Eulogio Robles: "El intérprete oficial del Protectorado es hombre de alguna edad y no me sirve de nada en mis investigaciones"13. Sin embargo, el mismo Robles menciona a José Manuel Huento en al menos dos artículos etnográficos, como informante de historias vividas por su padre. (Robles 1940)

a quien se sumó como capitán a las tropas de Gregorio Urrutia en la ocupación de Temuco (década de 1880). (Guevara 1913: 162)

ARNAD, Fondo IGCI, vol. 44, Robles a Inspector, 6 de marzo 1902 y 11 de julio 1902.

10 UMCE, Fondo Lenz, carta de Eulogio Robles a Rodolfo Lenz, Temuco, 30 de abril del 1910.

11 AHN, Fondo Intendencia de Cautin vol. 1898-1925 y vol. 1916-1918.

12 ARA, Causa civil del Primer Juzgado de Letras de Temuco, rol n 00343, caja 2.

13 UMCE, Fondo Lenz, Eulogio Robles a Rodolfo Lenz, Temuco, 30 de abril del 1910. 
Poco después del nombramiento de Urrutia Loncon como escribiente, en diciembre 1917 el protector Mozó contrata como portero-intérprete a Antonio Catrileo, quien ya en 1874 oficiaba de Intérprete juramentado en el Juzgado de Angol. La familia Catrileo es una antigua familia de ülmenlonkos y a principios del siglo XX destacaba el "cacique civilizado" Juan Catrileo como importante empresario agrícola y miembro fundador de la Sociedad Caupolicán de Temuco. De manera que de cuatro intérpretes que hemos identificado en el Protectorado de Cautín, tres provienen del trabajo en Juzgados, y Urrutia Loncon, el más joven, había realizado estudios secundarios, lo que le permitirá ser contratado como escribiente oficial. Además, dos de ellos, Morales y Urrutia, poseen nombres españoles, es decir, son descendientes de familias emparentadas por lakutun ${ }^{14}$ con autoridades criollas, y los otros dos, Catrileo y Huento, son hijos de connotados lonkos.

\section{Protectorado de IndíGenas de VALdivia}

En 1907, un año después de creado el Protectorado de Indígenas de Valdivia, esta oficina aún no cuenta con intérprete ni escribiente oficiales. El protector Carlos Irribarra se apoya en la práctica con el intérprete huilliche Manuel Antipil, quien aún no ha sido contratado. El Inspector de Colonización le escribe al Ministro de Relaciones Exteriores y Colonización, acerca de la necesidad de agilizar esta contratación como condición indispensable del funcionamiento del Protectorado:

para poder desempeñar el puesto i cumplir las obligaciones que le están encomendadas es indispensable el intérprete para comunicarse con los indígenas. Sin embargo, esta necesidad tan evidente no ha merecido la atención de los poderes públicos. Con la esperanza de ser nombrado presta sus servicios a mérito como intérprete el indígena Manuel Antipilo, pero como estas esperanzas amenazan desvanecerse, Antipilo desea retirarse de la oficina. ${ }^{15}$

14 El Diccionario de Augusta define laku como "el abuelo paterno y también los nietos del mismo; el tocayo" y la práctica del lakutun como "darse regalos mutuos dos tocayos para celebrar su amistad".

15 ARNAD, Fondo MINREL, vol. 1304, Inspector a Ministro, 26 de marzo 1907. 
Antipil solicita entonces un aumento de sueldo de 30 a 40 pesos mensuales ${ }^{16}$, ante lo cual el Protector propone que el Estado lo contrate como porterointérprete y a la vez "mozo" (que hace tanto tareas de aseo de oficina como de ayudante en salidas de terreno). El protector Irribarra argumenta al Inspector que en vez de tener que pagar 80 pesos en dos empleados diferentes, le pague 60 pesos a Antipil quien se encargaría de las tres labores.

Esta fórmula no hace más que formalizar contractualmente la pluralidad de funciones que se esperaba de los mapuches como portero-intérpretes, guías, baqueanos, mozos o alarifes, cuando el Protector de Indígenas realizaba salidas a terreno, para visitar una comunidad, una jefatura, una ceremonia o una reunión política. La multiplicidad de roles y tareas encomendadas a los mediadores recuerda también la de los antiguos personeros coloniales, como capitanes de amigos y lenguaraces, tratándose en este segundo caso, no solo de traductores, sino también de negociadores, conocedores de caminos, vados y rutas, diplomáticos fronterizos, mensajeros confidenciales, avivadores de intrigas y supervisores en terreno. De manera que, además de sus exigentes tareas de mediación, la agotadora movilidad geográfica y la precariedad de su posición en la administración pública, destacan algunos personajes que se "especializaron" en estas funciones, circulando eventualmente entre diferentes instituciones estatales.

En muchos casos, los porteros-intérpretes no pasarán de algunos años en el cargo. El citado Manuel Antipil durará tres años en el Protectorado de Valdivia, ya que 1910 es contratado en su reemplazo el joven Manuel Aburto Panguilef, quien había estudiado en la Misión Araucana de los anglicanos en Quepe, recibiendo luego formación en teología para convertirse en misionero.

Manuel Aburto Panguilef era nieto de Luis Aburto Ayñamko, quien adopta por alianza el laku de una connotada familia hispano-criolla de "comisarios de naciones" de la región de Valdivia, funcionarios coloniales a cargo de la mediación política con los indígenas. El primero de estos comisarios fue Francisco Aburto, nombrado por Ambrosio O'Higgins en 1793 en reemplazo de los Uribe y Jaramillo que ocupaban el cargo en el siglo XVIII. En el año 1821, su hijo Francisco Aburto Ramírez asume el cargo. Es probablemente con Aburto Ramírez que se vincula por alianza el lonko José Cayo Ayñamko de Niguen, adoptando el nombre Aburto, el que trasmitirá a su hijo Luis Aburto Ayñamko, abuelo de Manuel Aburto Panguilef. Luis

\footnotetext{
16 Para entonces, Antipil (también mencionado como Antifilo) aún no tiene su nombramiento oficial. El protector Ibarra señala que el mismo ha "estado pagando este sueldo que luego cobraré con viáticos y demás”. ARNAD, Fondo MINREL, vol. 1304, julio 1907.
} 
Aburto actuará entre 1860 y 1870 como joven secretario de su padre José Aburto Ayñamko y de su primo Juan Aburto, mientras que el criollo Manuel Aburto, hijo de Francisco Aburto, actuaba de "comisario de naciones". Luis Aburto será luego mencionado en varias crónicas como "cacique civilizado", y fue el padre del afamado lonko secretario de Juan Kalfukura en las Pampas y tío de Aburto Panguilef, Bernardo Aburto Namuncura (Treutler 1958: 419; Guevara 1913; Parentini 1994: 77; Menard 2013: XVII-XXI). De manera que Manuel Aburto Panguilef proviene de un linaje con varias generaciones de lonkos letrados, dirigentes y mediadores políticos, que además había establecido una temprana alianza con funcionarios estatales.

El entonces joven intérprete Aburto Panguilef tampoco durará muchos años en el cargo, ya que se dedicará a la creación de organizaciones mapuche hasta ser Presidente vitalicio de la Federación Araucana, una de las más importantes organizaciones mapuches de la primera mitad del siglo $\mathrm{XX}$. En una de sus primeras entrevistas como dirigente de la Sociedad de Protección Mutua de Loncoche, Aburto señala que es durante su servicio en el Protectorado cuando empezó "a preocuparse de la cuestión de las leyes" (Aburto 1923). En 1916, deja Valdivia para instalarse en Pitrufquén como ayudante de un gabinete de abogados, que lo apoyan para que estudie derecho en Santiago, pero este decide finalmente dedicarse completamente a la actividad política y cultural (Menard 2013: 24-25). Sin embargo, el paso de Aburto por el Protectorado lo llevará a valorar las Leyes de Radicación, y también lo convencerá de la necesidad de reivindicar el derecho consuetudinario y el rol de los dirigentes mapuche en la administración de justicia. Como señaló su hijo Germán Aburto, el "portero-intérprete" Aburto resignificó su tarea de lenguaraz en una mediación plenamente jurídica: "mientras que era lenguaraz, venía uno, venía otro convocados, y él total que era el juez el que fallaba, no ve que si el mapuche no sabía hablar castellano, y el juez tampoco, total que él era el juez" (cit. en Menard 2013: 24). Aburto Panguilef será reemplazado en el Protectorado de Valdivia por Guillermo Jaramillo Valle, quien luego de un par de años en la función, se retira en julio de 1915, y es reemplazado por José Tripaillante. La familia Jaramillo Valle de Villarrica, al igual que la familia Aburto, recibió su nombre por lakutun con un comisario de naciones que actuó hacia 1820, en este caso Pedro Jaramillo, y está emparentada con Adriano Mera Jaramillo, quien actuó de lenguaraz y baqueano de los viajeros Döll y Treutler en 1859 (Treutler 1861, Ulloa 2019). De manera que en este Protectorado también vemos que participan varios intérpretes huilliches de apellidos españoles, descendientes de familias antiguamente vinculadas como mediadores con el mundo hispano-criollo. 


\section{Comisión RADICADORA DE INDÍGENAS}

Como señalamos, la Comisión de Radicación era la institución encargada de asignar las tierras que el Estado reconocía como propias a los mapuches. En un principio, la Comisión compartía el intérprete con el Protectorado de Indígenas, pero ya en 1900, contaba con su propio intérprete, por la gran cantidad de solicitudes que tenía que atender. En ese cargo destacaron dos porteros-intérpretes y un escribiente mapuche. Felipe Reyes Millan, "de nombre español pero araucano de estirpe" (Guevara 1911: 5), emparentado a los Ñamko de Boyeco, quien aprendió a leer y escribir en castellano en la escuela misional capuchina de Temuco, y oficiará como intérprete en la Comisión desde cerca de 1900 hasta 1906, año en que es traspasado al mismo cargo en la Oficina de Mensura de Tierras. En 1914, Felipe Reyes consigue una beca de estudios superiores para su hijo Ramón Reyes, quien había estudiado con Tomás Guevara en el Liceo de Temuco. (Pavez 2003)

En 1906, Reyes es reemplazado en la Comisión Radicadora por Pedro Juan Melin quien actuará como intérprete oficial de la Comisión hasta al menos $1918^{17}$. Este intérprete provenía de una conocida familia abajina que se vinculó tempranamente con la República. Sus parientes antiguos Domingo Melin y su hijo Fermín Alejo Melin, descendientes del lonko Meliñamku, fueron enviados a estudiar con los wingkas, el primero, a la misión de Nacimiento y el segundo, en la Escuela Normal en Santiago. Ambos por lo tanto leían, escribían y eran bilingües mapudungun-castellano. Domingo Melin heredó la jefatura de familia, hasta que es asesinado en 1880. Fermín Melin por su parte fue escribiente e intérprete de la gobernación de Angol hacia 1870. Ambos murieron asesinados en 1880 por militares chilenos. (Pavez 2008: 68-69)

Tanto Felipe Reyes como Pedro Melin provienen entonces de familias con al menos dos generaciones de parientes alfabetizados en escuelas, y cercanas a los agentes estatales chilenos. Y ambos se mantuvieron por más de una década al servicio del aparato estatal.

17 ARNAD, Fondo MINREL vol. 1304, 21 febrero 1907; AHN, Fondo Intendencia Cautín 1916-1918. 


\section{INTÉRPRETES “TINTERILLOS”}

Los archivos del Protectorado, de las Intendencias regionales y de la Inspección de Colonización muestran que la capacidad de algunos mapuches de plantear sus reclamos y demandas, dirigiéndolas por escrito a las autoridades (y especialmente al gobierno central) generaba mayor atención y preocupación por responder a estos pliegos que aquellas demandas que eran formuladas en forma oral en las audiencias presenciales. Sin embargo, esta producción de documentos escritos y/o firmados "a ruego" por mapuches generaba también ciertas aprensiones y desconfianza en los propios Protectores, por las razones que expone el Protector de Valdivia Carlos Irribarra en su Memoria del año 1907:

Contamos por cientos en nuestra oficina las solicitudes, en papel sellado o en simple, redactadas i suscritas a ruego por individuos que se ocupan de estafar unos cuantos pesos a los indíjenas que concurren al protectorado haciéndoles creer que deben presentarse por escrito. [...] Hemos tenido que arrojar uno por uno a los ajentes oficiosos $\mathrm{i}$ apoderados que acompañaban a los reclamantes en las audiencias del Protectorado. No es aventurado afirmar que el noventa por ciento $(90 \%)$ de las solicitudes que llegan al Ministerio de Colonizacion, sean obra de esos compadecidos. La esperiencia nos autoriza a creer que del diez por ciento $(10 \%)$ restante hai sólo seis con fundamentos atendibles i que las cuatro (4) que quedan son, con raras escepciones, inspiradas por personas que buscan en el indíjena al instrumento para alcanzar algo de la esclusiva conveniencia del inspirador.

Conviene llamar la atencion a la letra i al estilo de esas numerosísimas presentaciones. A veces nos llegan cinco o mas solicitudes diversas en peticion de informes, que exhiben la misma letra i la misma reduccion i firmadas a ruego por un mismo individuo. Idéntico se observa en las presentaciones al Protector. Si se tuviera cuidado de examinarlas en sus detalles, se tendria el cuadro mas decidor de que el ochenta por ciento $(80 \%)$ de las de la provincia de Valdivia son siempre de puño i letra de las mismas cuatro personas. Igual observacion merecen las de Llanquihue. Este dato demuestra que ellas se deben, en su mayor parte, a insinuaciones de terceros que esplotan la ignorancia i el bolsillo. Nos consta, por la confesion de los indíjenas que éstos han pagado hasta veinticinco pesos (\$25) por una solicitud de proteccion en papel sellado presentada a esta oficina.

Una continuada propaganda del Protector en contra de esas presentaciones inútiles ha venido concluyendo con ese negocio innoble. Cerradas las puertas de esta oficina a esos libelos, el tinterillaje continúa su comercio 
esplotándolo con el envío de su artículo a las altas oficinas de la capital. Así se esplica esa cantidad enorme de peticiones de amparo, etcétera, que llegan a la Moneda sin haber pasado previamente por el Protectorado. De aquí la dificultad del Protector para informar con conocimiento de causa sobre ellas". (Irribarra 1908: 220-221)

Los llamados "tinterillos" aparecieron en el mundo fronterizo asociados precisamente al despliegue de las lógicas jurídicas y notariales de la legalización de la ocupación y propiedad de la tierra por colonos nacionales. Luego los propios mapuche tendrán que recurrir a ellos para tener "defensores" en sus reclamos formales. La producción del "papeleo" jurídico de la frontera hizo proliferar el "tinterillaje", no solo en notarías y tribunales locales sino también para la documentación que se enviaba a Santiago. Hacia 1900, se contaban en Temuco 27 bufetes de abogados con sus equipos de tinterillos (Bengoa 2000: 358). La existencia de estos mediadores jurídicos molestaba a los Protectores que veían en ellos un entorpecimiento en el cumplimiento de su responsabilidad de defender a los indígenas. Por eso los reparos del protector Irribarra de Valdivia, que seguía señalando en su exposición:

¿A qué conduce ese papeleo, ese cambio de notas etc., en estas oficinas públicas cuando las de arriba las envían en Informe a las de abajo? [...] Es ya tiempo que la corruptela deje de tener fuerza de lei de procedimiento administrativo. Pasar por sobre una oficina cuando se trata de asuntos que la lei le encomendó conocer especialmente, importa rodearla de desprestijio, matarle su autoridad moral, a la par que aumentarle inútilmente su labor.

Examínese donde está el fin práctico de las solicitudes de amparo etc., que desentendiéndose del Protectorado llevan los indíjenas al Ministerio. $\mathrm{Si}$ en esta alta reparticion se proveyeran: 'Ocurra donde corresponda' es seguro que en cortísimo tiempo desaparecerían esas montañas de papel formadas con las presentaciones [...] i se cegaría para siempre una fuente que esplotan los tinterillos. Con la adopcion de este temperamento iría desapareciendo ademas, poco a poco, el espectáculo que anualmente dan con su visita grupos de araucanos en el palacio de la Moneda. (Irribarra 1908: 221-222)

Estas preocupaciones del Protector de Valdivia muestran las limitaciones del proyecto proteccionista, en la medida en que se sustenta en una ideología de tutela paternalista, verticalista y burocratizada de los derechos mapuches. La ideología tutelar reproducía los principios de la doctrina romana e indiana respecto a considerar a los indígenas como personas "miserabilis" o menores, que requerían "tutores" para ejercer sus derechos (Cuena 1998). Aunque 
la constatación del negocio de "tinterillaje" y su condena es relevante, el argumento termina en una defensa corporativa del Protectorado en la cadena de conductos burocráticos regulares. Esto porque al saltarse este aparato de mediación jurídico-administrativa específicamente destinado a ellos, los mapuches estarían fomentando el cuestionamiento estatal a su pertinencia y eficiencia en la resolución de los conflictos de tierra. Pero además, porque este salto administrativo y geográfico (el viaje a Santiago de documentos y comitivas) reinstala una simetría política ampliamente conocida en la historia mapuche (Foerster y Menard 2009), pero contradictoria con la ideología proteccionista de la tutela.

Es importante destacar que la molestia de Irribarra, compartida por varios Protectores, está dirigida a la condena de los tinterillos en su capacidad de producción de documentos, el llamado "papeleo de la frontera". Si bien la práctica de los tinterillos se prestaba a todo tipo de abusos, engaños y extorsión de recursos a los mapuches que creían en ellos, la lógica documental del tinterillaje fue impulsada desde los primeros años de la colonización al sur del Biobío como estrategia clave para la validación notarial y judicial de las inscripciones de tierras por parte de los colonos chilenos. En ese sentido, el Protector tampoco percibe que esta lógica fue apropiada por jefes de "reducciones" y otros dirigentes en la medida en que la documentación escrita (y sellada con timbre y estampillas oficiales) parecía ser la única que otorgaba validez jurídica a sus demandas y reclamos.

De hecho, muchos documentos del Ministerio de Colonización y de la Inspección General de Colonización muestran que efectivamente los aparatos de Estado se movían más diligentemente de arriba hacia abajo, mediados por la documentación sobre la cual las autoridades más altas (Ministro o Inspector) pedían explicaciones a los Protectores. El profesor, escritor, traductor y futuro diputado mapuche Manuel Manquilef apunta al mismo argumento cuando denuncia "El tinterillaje establecido a firme por el Gobierno":

[De] La violación de las leyes, las componendas, robos al Fisco y a los indios se hace responsable al tinterillo. Esta es una falsedad. Los responsables de todo esto son los juzgados, oficinas públicas y demás autoridades que rechazan al abogado honrado y han necesitado de aquellos para que les ayuden a consumar sus malas actuaciones. El tinterillo es mejor que aquellos y no es sino una causa instrumental. Es el Gobierno que ha fomentado los procedimientos tinterillescos y ha necesitado de elementos que se prestaran a ser sus agentes en cuanta injusticia cometiera y que pudieran servir también a los civilizados mandados acá de amparador y defensor de sus latrocinios. (Manquilef 1915: 15) 
$\mathrm{Al}$ reconocer esta apropiación de la lógica del tinterillaje, se percibe que los tinterillos eran de procedencia heterogénea, y que algunos mapuche letrados también realizaron esas labores, probablemente sin el mismo ánimo de lucro que tenían otros extorsionadores, cosa en la que los Protectores no están de acuerdo. Así por ejemplo, en el año 1914, los archivos de los Protectorados constan de cartas de Juan Sandoval, Andrés Manquenahuel, Ignacio Cheuquenao, Alberto Martínez, Domingo Curaqueo, José Segundo Calfio, Francisco Carileo, quien escribe en representación de Ignacio Cheuquehuala y doce otros mapuches, Pascual Yaitul y Marcelino Llancau, quienes escriben un telegrama directamente al ministro, además de los dirigentes de la Sociedad Caupolicán como Manuel Neculman y Basilio García, que escriben a máquina sus representaciones ${ }^{18}$. Al ser alfabetizados y tener un buen manejo del castellano, estos demandantes obtendrán mayores consideraciones del aparato jurídico, lo que en sí mismo constituía un incentivo para que otras familias decidieran impulsar el aprendizaje del castellano entre sus descendientes, como necesidad imperiosa para la defensa de sus tierras.

Los mapuche letrados y con algún conocimiento de la procedimentalidad jurídico-burocrática, es decir los tinterillos mapuche, serán especialmente condenados y desvirtuados por los Protectores, que los acusan de incitar a los mapuches a enfrentarse a la institución y reclamar contra ella, como señala el Protector de Llanquihue en su Memoria de 1912, que se asemeja bastante a las anteriores críticas de Irribarra:

Una palabra mas sobre las reclamaciones que a veces se formulan contra el proceder de esta oficina. Hai un pequeño contadísimo número de indíjenas que no poseyendo ya ni una vara de terreno, ni ánimo para el trabajo, han abrazado la profesión de acompañar i dirijir a los indíjenas en todas sus dilijencias, ya sea en el Protectorado, en la Gobernación, policía, etc. Como esplotan a los infelices en forma a veces vergonzosa, el infrascrito ha tomado algunas medidas contra ellos. Son éstos los que van a Temuco i Santiago con quejas i reclamaciones contra el infrascrito, i fácil es comprobar, que son siempre los mismos individuos, i nadie mas, i que sus exposiciones son siempre inexactas o sin fundamento. (Schwerter 1913: 140-141)

Se revela aquí la dificultad de la ideología tutelar para ver a los mapuches como sujetos que producen sus propios agenciamientos, siendo siempre vistos como sujetos manipulados o manipulables (por sacerdotes y otros 
agentes públicos o privados) (Le Bonniec y Berho 2018). En varios casos, estos tinterillos mapuches también provenían de familias más cercanas a la frontera y con relaciones más estrechas y antiguas con los misioneros y agentes estatales de la República, familias que buscaron en el siglo XIX formar a su descendencia en el bilingüismo, práctica descrita por el rector del Liceo de Temuco, Tomás Guevara, como sigue:

Los caciques no resistian la permanencia de sus hijos en los colejios misionales: tenian particular interes en que aprendieran a leer i escribir para que revisaran los documentos orijinados de sus transacciones. Hasta el dia persiste entre los jefes de familia la costumbre de enviar al colejio al hijo mayor para que sea mas tarde un develador o un defensor de las argucias i avidez del leguleyo [...] Lo que se solia hacer por las autoridades civiles i militares creyéndose una gran obra en favor de la cultura indíjena, era conseguir el ingreso de algunos hijos de caciques a la escuela normal de preceptores de Santiago. Mas, esta medida no ejercía preponderancia alguna en el adelanto intelectual del araucano, porque estos individuos, escepto uno que otro, volvían a la vida bárbara al ponerse en contacto con los suyos. (Guevara 1904: 69)

A continuación, Guevara presenta a su "antiguo colaborador" etnográfico Lorenzo Coliman, de la gran familia nagche o abajina de los Colipi, a quien da como ejemplo paradigmático de esta "vuelta a la vida bárbara" del mapuche letrado y bilingüe, mencionando además sus actividades de tinterillo:

Lorenzo Coliman, nuestro colaborador en muchos puntos de sociolojia araucana, es hijo de un cacique de Puren. Despues de adquirir en la mision de Collipulli los conocimientos primarios, ingresó en 1876, por intermedio del jeneral Saavedra, a la escuela de preceptores de Santiago. Estudió tres años, i en seguida, en vez de ir a enseñar a los niños de su tribu, se incorporó en 1879 al ejército que espedicionó al Perú. Concluida la guerra, vuelve a los lares de sus antepasados, para casarse a la usanza de los suyos, vivir de ruca en ruca, arrendar sus terrenos a los ávidos aparceros i vagar por las oficinas de Angol i Temuco traduciendo al castellano las querellas i peticiones del perseguido mapuche. (Guevara 1904: 69)

Guevara no señala aquí que entre 1887 y 1892, Coliman trabajará como intérprete juramentado en el Juzgado de Angol, al igual que su pariente Juan Colipi, y que en los años siguientes no solo actuará de tinterillo, sino también en "las tareas de enseñar a leer i escribir a niños indígenas" como profesor itinerante de las reducciones (Guevara 1911: 4). Este perfil de mapuche letrado que alterna entre actividades de preceptor y de mediador jurídico, 
es un tanto diferente al del antiguo lenguaraz, muchas veces mestizo, que tradicionalmente generaba sospechas de parte de los agentes wingkas.

Otro caso destacable de "tinterillo mapuche" es el de Manuel Aburto Panguilef, intérprete y dirigente mapuche ya mencionado como porterointérprete, quien formará parte de esos tinterillos "que han abrazado la profesión de acompañar i dirijir a los indíjenas en todas sus dilijencias", como señala molesto el protector Schwerter (1913: 140). Lo destacable de su trayectoria es que luego de su inserción institucional como intérprete del Protectorado de Valdivia (1910-1916), Aburto se autonomiza como ayudante de un bufete de abogados hasta volverse él mismo un abogado informal (tinterillo). Este proceso de "des-institucionalización" no implicará una renuncia al trabajo de escritura y mediación jurídica sino al contrario la afirmación de una posición "autonomista" respecto a los aparatos jurídicos, posición con la que reforzará su comprensión jurídico-política de la importancia de un "archivo propio" del pueblo mapuche, que incluyera un registro civil propio y el desarrollo de una jurisprudencia del "derecho propio", todo lo cual impulsará como dirigente profético desde lo que llama la "notaría celestial" de su organización política, la Federación Araucana. (Menard y Pavez 2005)

\section{INTÉRPRETES “LENGUARACES”}

Ya desde épocas de la conquista, la valoración de los intérpretes conocidos como "lenguas" o "lenguaraces" fue ambigua: declarados indeseables pero fatalmente indispensables, las crónicas y la historiografía misma les llegó a considerar culpables de fracasos militares y traiciones (Payàs y Garbarini 2012, Ulloa 2009 y 2019). Lo cierto es que para prescindir de ellos no había más remedio que aprender la otra lengua y al mismo tiempo procurar, con el tiempo, castellanizar. Mientras eso no sucedía, controlar el ejercicio de sus funciones no era cosa fácil para los funcionarios estatales, que veían a veces tergiversadas sus intervenciones por estos mediadores, ya fuere porque tenían intereses en el asunto, por incompetencia o por mala fe.

La figura del lenguaraz y las connotaciones ambivalentes sobre su función de mediación socio-político-lingüística seguirán presentes en la frontera a principios del siglo XX, como se puede ver en la descripción que hace el protector Robles de uno de los más famosos lenguaraces de la época, el "simpático mestizo" Chelle Burgos: 
Ya en espera con el objeto de servir de testigo, ya en trajines para conducir ante la justicia a individuos que deberían declarar en pleitos en que con frecuencia se promueven y enmaraña a los indios, Chelle Burgos revoloteaba continuamente por los juzgados, y no sólo tales trabajos pesaban sobre sus hombros, sino que también contribuía a las tareas judiciales 'pasando la lengua', esto es, sirviendo de intérprete en los litigios en que estaban complicados intereses mapuches y en los procesos criminales seguidos contra ellos. Chelle Burgos no era re-mapuche, indio puro, sino champurria, mezcla de europeo y de araucano, tal como lo delataba su aspecto: bajo de estatura, grueso y de poca barba, como la generalidad de los indígenas, pero de ojos verdes y de cutis claro.

Como nadie está libre de 'pelambres' o sea, de habladurías mal intencionadas, Chelle fue víctima de muchos de ellos, pues murmuraban algunos de sus coterráneos que se creyeron perjudicados con su intervención que no siempre era exacto en sus declaraciones, sino que variaba los hechos con la mira prudente de no echarse encima la mala voluntad de la contraparte, sobre todo, si tenía con ella relaciones de amistad, o con el propósito muy humano de obtener alguna ventaja material y no lo incluían entre los kumeketuwunche, es decir entre la gente de buena procedencia, de clara estirpe, que jamás obscurece la verdad ni mancha los labios con la mentira; pero es de advertir que no toda la fama pública se contaminaba con esta opinión desfavorable, porque oímos más de una vez defenderlo enérgicamente de tales 'pelambres'. (Robles 1940: 113-114)

El lenguaraz Chelle Burgos era para entonces el último descendiente de una familia de lenguaraces en la que destacó el antiguo Rafa Burgos, quien fuera intérprete en el conocido Parlamento de Tapihue (1825), y padre de dos Manuel Burgos, también destacados como lenguaraces desde mediados del siglo XIX (Ulloa 2019). El nombre español indica que en algún momento este linaje se emparentó con agentes hispano-criollos, pero además que en el caso de Chelle Burgos se trata de un champurria o mestizo. Es interesante también destacar que a pesar de su tradición en el oficio de mediación, los Burgos no son reconocidos como estirpe re-mapuche y por lo tanto su palabra puede ser cuestionada.

La cuestión del mestizaje, que afecta a muchos de los lenguaraces fronterizos identificados como champurria, es decir, hijos de mapuche y wingka, parece haber sido un factor que los ponía en algún momento bajo sospecha de ambivalencia en sus intereses. No tenemos claro en qué momento se empieza a construir esa imagen, pero es posible que tenga que ver con las lógicas de ocupación territorial chilena en el siglo XIX y los enfrentamientos entre parcialidades que esta desató. Además, es importante destacar que los mestizos tenían un acercamiento privilegiado al bilingüismo, 
al ser generalmente hijos de mujeres chilenas, las chiñurras cautivas casadas con lonkos polígamos, por lo que adquirían el castellano como lengua materna. Durante el periodo colonial hispano, chiñurras y champurrias, ambos mapuchizados, gozaban de amplio estatus, pero en la segunda parte del siglo XIX, debido a la política de conquista impulsada por el Estado chileno y el consecuente cierre etno-racial de la sociedad mapuche, cayó sobre estos cierta desconfianza.

La tendencia de los lenguaraces a ampliar el sentido de la traducción hacia una mediación más propiamente política, es comentada por el ingeniero Soto al protector Irribarra, a quien señala que ha optado por preparar un léxico para su uso en las comisiones de ingeniería que efectúa en las reducciones, a fin de no ser burlado por el intérprete.

He confeccionado, señor Protector, una cartilla del dialecto araucano, con las palabras i frases que mas directamente se relacionan con mi trabajo, para darme a entender entre ellos, porque hai reducciones de indios, lejanas de centros civilizados, que desconocen por completo nuestro idioma. Anteriormente, me entregaba a los buenos servicios del lenguaraz, tipo del indio valiente, astuto i sobre todo embustero, que no se conforma con traducir lo que oye, sino que inventa i concluye por poner en boca de otro, lo que él piensa, haciéndose indispensable llamarlo al órden por medio de los Carabineros i que traduzca corto i al pié de la letra. Estos inconvenientes se remedian con la cartilla. (Soto en Irribarra 1911: 650)

La preocupación del ingeniero revela así la frustración del agente de Estado al no poder controlar al individuo intérprete y sus intereses personales (o los que él representa). Por otra parte, muestra que la no estandarización de la traducción favorece y fortalece el rol de mediación política e incluso judicial de los lenguaraces y tinterillos mapuches, especialmente los que actúan en forma independiente o para-estatal, sin ser institucionalizados.

\section{EDUCACIÓN Y CASTELLANIZACIÓN}

En este artículo hemos intentado mostrar las diferentes figuras del mediador sociolingüístico que se van perfilando en el proceso de ocupación del Ngulumapu y de reducción de los mapuches en comunidades. Hemos visto cómo los intérpretes institucionales de las oficinas de los Protectores de 
Indígenas y de la Comisión de Radicación responden a una sociogénesis que tiene sus antecedentes en familias "especializadas" de lenguaraces, y cuya especialización remonta a todo el siglo XIX e incluso al periodo colonial. Asimismo, hemos visto la emergencia de la figura de los intérpretes tinterillos en el seno de estas mismas tradiciones familiares. La existencia de estas tres figuras de mediadores que actúan durante el período reduccional -intérpretes institucionales, intérpretes tinterillos, interpretes lenguaracesestán en estrecha relación con las lógicas de educación y alfabetización que desarrollaron ciertas familias mapuches durante el siglo XIX, entregando sus hijos a escuelas misionales o públicas para su educación formal en castellano. Algunas de estas familias, que proveyeron de mediadores sociolingüísticos al proceso jurídico y administrativo de la Radicación, fueron constituyendo una élite letrada mapuche que pudo defenderse de mejor manera ante el despojo territorial. Otras familias se beneficiaron de su constitución interétnica que facilitaba la formación informal bilingüe de sus descendientes. Sin embargo, la gran mayoría de los mapuche no tuvo estas oportunidades durante el periodo reduccional.

Por eso, los Protectores de Indígenas, y particularmente Eulogio Robles, serán insistentes en la necesidad de universalizar la escuela primaria entre los mapuche. La educación y especialmente la alfabetización eran consideradas elementos fundamentales de lo que se entendía por "civilización de los araucanos": la sustitución de su modo de vestir, de habitar, de sus costumbres matrimoniales (poligamia) y de su idioma. Para este proyecto "civilizatorio" declaradamente asimilacionista, la escuela era la institución clave que los Protectores llamaron a universalizar. Aunque no tuviera facultades para poner en práctica una política masiva de educación pública, Eulogio Robles apoyó anualmente el envío de entre 10 y 15 mapuche a cursar estudios de educación superior en las ciudades de Concepción, Chillán y Santiago.

Por otro lado, y en la misma línea civilizatoria, que hace recaer en la República y ya no tanto en los misioneros la responsabilidad de la educación y la alfabetización, el Protector de Osorno argumenta al Inspector General la necesidad de crear al menos cuatro escuelas para indígenas en el Departamento:

Hai en este departamento mas de once mil indígenas que casi en su totalidad son absolutamente ignorantes. Varios caciques del departamento me han manifestado la necesidad de crear escuelas para indígenas $i$ he podido imponerme que hai varios centros de poblaciones indígenas en donde las escuelas encontraría una población escolar de mas de cien alumnos cada una. Se nota algo vergonzoso para nuestra cultura i es que hai indígenas ancianos que saben leer i escribir correctamente en 
cambio sus descendientes viven en la mas completa ignorancia debido a la falta de escuelas ${ }^{19}$.

Por su parte, el visitador de escuelas de Valdivia Anselmo de la Cruz trasluce su ideario al Protector de Cautín, señalando que: "Si los indijenas tuvieran escuelas, indudable es que asistirían a ellas, pero en la provincia escasean hasta para todos los habitantes, no sólo para ellos. A fin de instruirlos se necesitarian ubicar mas de treinta escuelas entre los de esta provincia" (Robles 1902: 201). Los informes de este y otros funcionarios celebran casi unánimemente la capacidad de aprendizaje de los mapuche, y mencionan especialmente la relación con la lengua dominante como cuestión principal del éxito del proceso de educación, alfabetización y "civilización". El visitador de escuelas de Cautín señala al respecto que los mapuche son "refractarios a los ramos científicos por las dificultades con que tropiezan para posesionarse del idioma; pero una vez que dominan el castellano, les es sumamente fácil adquirir cuanto se les enseñe". Para este agente ministerial, la mayor dificultad está en que "los araucanos viven retirados de los centros de poblacion i su estado de pobreza no les permite mandar a sus hijos a educarse en los pueblos". Sin embargo, destaca la diferencia de clase que permite que "los caciques acomodados les dan la educacion correspondiente, mandándolos a Temuco i aun a Chillan i a Santiago". (Robles 1902: 199)

El Protector de Cautín también valorará estas familias que buscan escolarizar a sus hijos: "Hai indíjenas que tienen grande interes en educar a sus hijos $i$ acuden a solicitar con empeño que se los admitan en los establecimientos de educación que sostienen misioneros católicos $\mathrm{i}$ protestantes. Hasta se cuentan algunos que con sacrificios los envian a las escuelas públicas i al liceo de esta ciudad" (Robles 1905: 191). Asimismo, el visitador de escuelas de Valdivia insistirá por su parte en que "Esos niños [indígenas] poseen facilidad para el aprendizaje de todos los ramos memorativos i de observacion i aplicacion practica, como dibujo, caligrafía, física, etc. Con rapidez admirable, teniendo algun cuidado, aprenden a espresarse correctamente en castellano, sin encontrar dificultades en la pronunciacion". (Informe, en Robles 1902: 200)

Otro espacio de alfabetización (y por lo tanto, de castellanización) destacado por el Protector de Arauco, Fernando Muñoz, en su Memoria del año 1913, es la conscripción militar, donde constata que:

19 ARNAD, Fondo MINREL, vol. 1436, 17 diciembre 1908. 
el indio por su carácter guerrero tiene gran entusiasmo por militar en las filas del Ejército; mas resulta, que ignorantes de las fechas en que se les hacen sus llamados no comparecen oportunamente con lo cual ordinariamente se ven procesados por la citada lei. No se ocultará a la penetración de usted las ventajas positivas que se adquirirían para el indíjena en la conscripción militar en orden a la instrucción, carácter i hábitos que en los cuarteles se les enseña. El indíjena es casi en su totalidad analfabeto i de aquí que tiene gran importancia el que hagan su servicio militar, lo cual seria fácil con que el Ministerio de Guerra impartiera al señor Intendente de esta Provincia i a los Gobernadores de Departamentos para que con la oportunidad debida notifiquen a los llamados al servicio militar. (Muñoz 1914: 108)

Diez años antes, Eulogio Robles había recogido el énfasis de los visitadores en la resistencia mapuche a la adquisición del castellano, constatando que el indígena "no quiere abandonar su idioma". Para enfrentar la situación, recoge una propuesta del profesor y lingüista Rodolfo Lenz respecto a la necesidad de una educación primaria en mapudungun: "Es inexacto si se dice que el indio no quiere enseñanza. Cierto que no le gusta estudiar el catecismo, nada mas cierto que no le gusta la enseñanza que se da en un idioma que no comprende. Pero establézcanse en medio de los indios pequeñas escuelas en donde se enseñen las primeras letras por parte de preceptores que sepan expresarse en idioma indio y que después comuniquen a sus alumnos conocimientos prácticos, los resultados no faltarán”. (Robles 1902: 197)

Estos informes dan cuenta de una realidad lingüística donde los intérpretes, profesionales y mediadores lingüísticos mapuches tienen una importancia fundamental en el periodo de la constitución de la propiedad reduccional ${ }^{20}$. Esto explica por una parte el posicionamiento jurídico aventajado de las familias mapuches que han trasmitido el bilingüismo a través de diferentes generaciones, y de las familias que consiguieron enviar tempranamente a las generaciones más jóvenes a escuelas chilenas, donde adquirieron competencias en el castellano y la escritura alfabética. Esta posición destacada en el proceso de constitución de la propiedad será sin duda un incentivo para otras familias y comunidades mapuches para la

20 Durán y Ramos (1987: 183) subrayan que el "fenómeno sociolingüístico fue, al mismo tiempo, factor y resultante de dentro del proceso histórico total" en el siglo XIX. Para ellas, el sistema de intermediarios fue, además, la demostración no solo de la coexistencia de las dos sociedades sino del funcionamiento de un Estado dentro del otro. Si bien no se refieren a la administración de justicia, consideran la importancia de los mediadores en lo que llaman el "área institucionalizada de contacto" chileno-mapuche. 
escolarización futura de sus hijos, y da cuenta de la incidencia de la ideología jurídica en la imposición de una ideología lingüística, donde la adquisición de la lengua dominante y su escritura se presentan como herramientas imprescindibles para la defensa de los derechos mapuches: una defensa presente y una defensa futura.

En un artículo etnográfico pionero sobre la castellanización de una comunidad mapuche lafkenche, Rodrigo Herrera (1999) propone una secuencia generacional del avance del castellano y el repliegue del mapudungun a lo largo del siglo XX. La generación mapuche nacida entre 1900 y 1925, es decir, durante el periodo de radicación en reducciones y de actuación de los Protectorados de Indígenas, habría sido aún formada como monolingüe en mapudungun. La generación siguiente (1925-1950) habría sido bilingüe, ya que se le trasmitió el mapudungun y lo siguió transmitiendo, en paralelo al aprendizaje del castellano como lengua ya dominante. $\mathrm{La}$ tercera generación (1950-1975) habría sido bilingüe mapudungun-castellano, pero dejo de transmitir la lengua nativa a la generación siguiente. La cuarta generación (1975-2000) quedó así totalmente monolingüe en castellano. Esta secuencia es elaborada en base a un registro etnográfico que tiene las particularidades histórico-geográficas de la Provincia de Arauco. Luego de un primer cuarto de siglo de monolingüismo dominante en mapudungun, la propia dinámica de constitución jurídica de la propiedad en ese periodo contribuyó a obligar a la sociedad mapuche a incorporar el castellano a su práctica lingüística, generando la primera generación masivamente bilingüe (1925-1950), principalmente por efecto de la escolarización universal que se refuerza con los gobiernos del Frente Popular. Esta generación fue también la que se ve obligada a la movilidad estacional laboral para buscar trabajo en los fundos, y la que inicia la migración masiva a las ciudades, por las estrecheces de tierra en las que la deja el proceso reduccional que culmina en 1930.

Finalmente, lo que muestra nuestra investigación, es que el bilingüismo se universalizó a destiempo del proceso jurídico de la constitución de la propiedad, de manera que cuando una gran cantidad de mapuches ya manejaban el idioma español, la adjudicación de tierras ya se había realizado y con gran perjuicio para ellos. Este destiempo es análogo al que se produce en la génesis del proceso reduccional, ya que la aplicación efectiva de las Leyes de Radicación por medio de la adjudicación de Títulos de Merced se inicia cuando la ocupación por colonos ya se ha establecido de facto y "legalizado" a través de innumerables procedimientos administrativos, notariales y judiciales. 


\section{REFERENCIAS BIBLIOGRÁFICAS}

\section{FuENTES DE ARCHIVO}

ARA - Archivo Regional de la Araucanía

Fondo Juzgado de Letras de Temuco

ARNAD - Archivo Nacional de la Administración

Fondo Ministerio de Relaciones Exteriores, Culto y Colonización

Fondo Inspección General de Colonización e Inmigración

UMCE - Universidad Metropolitana de Ciencias de la Educación

Fondo Rodolfo Lenz

\section{FueNTES DOCUMENTALES O INÉDITAS}

Aburto Panguilef, Manuel. 1923. Los fines que persigue la Federación Araucana de Loncoche. El Mercurio de Santiago, 20 de enero 1923.

1938. Manuscrito, inédito.

Arrieta, Javier. 1912. Memoria del Protectorado de Indíjenas de Malleco del año 1911. Ministerio de Relaciones Exteriores, Culto y Colonización. Memoria de la Inspeccion Jeneral de Tierras $i$ Colonizacion, pp. 611-620. Santiago de Chile: Imprenta i Encuadernacion Ercilla.

1914. Memoria del Protectorado de Indíjenas de Malleco del año 1913. Ministerio de Relaciones Exteriores, Culto y Colonización. Memoria de la Inspeccion Jeneral de Tierras i Colonizacion, pp. 99-100. Santiago de Chile: Imprenta i Encuadernacion Ercilla.

Bravo, Eleazar. 1914. Memoria del Protectorado de Indíjenas de Cautín del año 1913. Ministerio de Relaciones Exteriores, Culto y Colonización. Memoria de la Inspeccion Jeneral de Tierras $i$ Colonizacion, pp. 111-120. Santiago de Chile: Imprenta i Encuadernacion Ercilla.

Cerda, Daniel. 1911. Memoria del Protectorado de Indíjenas de Llanquihue del año 1910. Ministerio de Relaciones Exteriores, Culto y Colonización. Memoria de la Inspección Jeneral de Colonizacion e Inmigracion, pp. 441-457. Santiago de Chile: Imprenta i Encuadernacion Ercilla.

Irribarra, Carlos G. 1908. Memoria del Protectorado de Indíjenas de Valdivia y Llanquihue del año 1907. Ministerio de Relaciones Exteriores, Culto y Colonización. Memoria de la Inspeccion Jeneral de Colonizacion e Inmigracion, pp. 211-267. Santiago de Chile: Imprenta y Encuadernación Universitaria de S.A. García Valenzuela.

1909. Memoria del Protectorado de Indíjenas, Provincia de Valdivia, año 1908. Ministerio de Relaciones Exteriores, Culto y Colonización. Memoria de la Inspeccion Jeneral de Colonizacion e Inmigracion, pp. 352-360. Santiago de Chile: Imprenta y Encuadernación Universitaria de S.A. García Valenzuela.

1911. Memoria del Protectorado de Indíjenas de Valdivia del año 1910. Ministerio de Relaciones Exteriores, Culto y Colonización. Memoria de la Inspección Jeneral de Colonizacion e Inmigracion, pp. 433-440. Santiago de Chile: Imprenta i Encuadernacion Ercilla. 
1914. Memoria del Protectorado de Indíjenas de Valdivia del año 1913. Ministerio de Relaciones Exteriores, Culto y Colonización. Memoria de la Inspección Jeneral de Colonizacion e Inmigracion, pp. 121-130. Santiago de Chile: Imprenta i Encuadernacion Ercilla.

Labbé, Manuel. 1911. Memoria de la Oficina del Protectorado de Indíjenas de Arauco del año 1910. Ministerio de Relaciones Exteriores, Culto y Colonización. Memoria de la Inspección Jeneral de Colonizacion e Inmigracion, pp. 393-401. Santiago de Chile: Imprenta i Encuadernacion Ercilla.

Muñoz, Fernando. 1914. Memoria del Protectorado de Indíjenas de Arauco del año 1913. Ministerio de Relaciones Exteriores, Culto y Colonización. Memoria de la Inspección Jeneral de Colonizacion e Inmigracion, pp. 101-109. Santiago de Chile: Imprenta i Encuadernacion Ercilla.

Oñate, Manuel. 1911. Memoria del Protectorado de Indíjenas de Malleco del año 1910. Ministerio de Relaciones Exteriores, Culto y Colonización. Memoria de la Inspección Jeneral de Colonizacion e Inmigracion, pp. 403-411. Santiago de Chile: Imprenta i Encuadernacion Ercilla.

Robles, Eulojo. 1902. Anexo Num. 7: La labor de la oficina del año 1901. Ministerio de Relaciones Exteriores, Culto y Colonización. Memoria de la Inspeccion Jeneral de Tierras i Colonizacion, pp. 149-227. Santiago: Imprenta Moderna.

1903. Memoria protectorado de indíjenas del año 1902. Ministerio de Relaciones Exteriores, Culto y Colonización. Memoria de la Inspeccion Jeneral de Tierras $i$ Colonizacion, pp. 26-43. Santiago de Chile: Imprenta Cervantes.

1905. Memoria del Protectorado de Indíjenas del año 1904. Ministerio de Relaciones

Exteriores, Culto y Colonización. Memoria de la Inspeccion Jeneral de Tierras $i$ Colonizacion, pp. 179-204. Santiago de Chile: Imprenta Cervantes.

1907. Memoria del Protectorado de Indíjenas del año 1906. Ministerio de Relaciones

Exteriores, Culto y Colonización. Memoria de la Inspeccion Jeneral de Tierras $i$ Colonizacion, pp. 100-115. Santiago de Chile: Imprenta Nacional.

Schwerter, José. 1913. Memoria del Protectorado de Indíjenas de Llanquihue del año 1912. Ministerio de Relaciones Exteriores, Culto y Colonización. Memoria de la Inspeccion Jeneral de Tierras i Colonizacion, pp. 131-141. Santiago de Chile: Imprenta i Encuadernacion Ercilla.

\section{BibliografíA}

Almonacid, Fabí́n. 2009. El problema de la propiedad de la tierra en el Sur de Chile (18501930). Historia (Santiago) 42 (1): 5-56.

Bayle, Constantino. 1945. El protector de naturales. Sevilla: Escuela de estudios hispanoamericanos.

BengoA, José. 2000. Historia del pueblo mapuche. Santiago: Lom Ediciones.

Bonnet, Diana. 1992. Los protectores de naturales en la Audiencia de Quito. Siglos XVII y XVIII. Quito: FLACSO/ Abya-Yala.

Comaroff, Jean y John Comaroff. 1992. Ethnography and the Historical Imagination Ethnography and the Historical Imagination. San Francisco y Oxford: Westview Press.

Cuena Boy, Francisco. 1998. Utilización pragmática del derecho romano en dos memoriales indianos del siglo XVII sobre Protectores de Indios. Revista de estudios histórico-jurídicos 20. http://dx.doi.org/10.4067/S0716-54551998000200004 
Cunill, Caroline. 2012. Fray Bartolomé de las Casas y el oficio de defensor de indios en América y en la Corte española. Nuevo Mundo Mundos Nuevos [En línea], Debates, consultado el 25 de febrero, 2020. URL : http://nuevomundo.revues.org/63939 ; DOI : 10.4000/nuevomundo.63939

2019. La protectoría de indios en América: avances y perspectivas entre historia e historiografía. Colonial Latin American Review 28 (4): 478-495.

De la Torre Curiel, José Refugio. 2010. Un mecenazgo fronterizo: El Protector de Indios Juan de Gándara y los ópatas de Opodepe (Sonora) a principios del siglo XIX. Revista de Indias LXX (248): 185-212.

Delgado, Daniela y Elsy Curihuinca. 2012. Interculturalidad en juicio: el derecho del indígena a comunicarse en su propia lengua. Vivat Academia 118: 61-75.

DurÁn, Teresa y Nelly Ramos. 1987. Incorporación del español por los mapuches del centro sur durante el siglo XIX. Lenguas Modernas 14: 179-196.

Foerster, Rolf y Sonia Montecino. 1988. Organizaciones, Lideres y Contiendas Mapuches (1900-1970). Santiago: Ediciones CEM.

Foerster, Rolf y Fernanda Villarroel. 2008. Los hermanos Budaleo como caciques gobernadores del Ayllarehue de Arauco y las transformaciones del Pacto Colonial (18201889). Cuadernos Interculturales 6 (11): 146-171.

y ANDRÉ MenARD. 2009. Futatrokikelu: don y autoridad en la relación mapuchewingka. Atenea 499: 33-59.

GinzBurg, CARLo. 2008. Indicios: Raíces de un paradigma de inferencias indiciales. En Carlo Ginzburg. Mitos, emblemas, indicios. Morfología e historia, pp. 138-176. Barcelona: Gedisa.

Guarda, Gabriel. 1968. Los caciques Gobernadores de Toltén. Boletín de la Academia Chilena de la Historia XXXV (78): 43-68.

Guevara, Tomás. 1904. Costumbres judiciales i enseñanza de los Araucanos. Santiago: Imprenta Cervantes.

1911. Folklore araucano: refranes, cantos, procedimientos industriales, costumbres prehispánicas. Santiago: Imprenta Cervantes.

1913. Las últimas familias y costumbres araucanas. Santiago: Imprenta Barcelona.

Herrera, Rodrigo. 1999. El castellano en Ponotro. Usos y valoraciones de una lengua impuesta. Revista de la Academia 4: 93-118.

Le Bonniec, Fabien y Pamela Nahuelcheo. 2017. La mediación lingüístico-cultural en los tribunales en materia penal de la Araucanía. Revista de Llengua i Dret/ Journal of Language and Law 67: 279-293.

y Marcelo Berho. 2018. El abogado de los indios y la constitución de la propiedad austral en Chile. Relevancia sociojurídica pasada y presente en las cartas del padre Sigifredo de Frauenhäusl. En Gabriel Pozo M. (ed.). Expoliación y violación de los derechos humanos en territorio mapuche. Cartas del padre Sigifredo. Misión de Panguipulli, año 1905, pp. 435-451. Santiago: Ocho Libros.

León, Leonardo. 1999. Apogeo y ocaso del Toqui Ayllapangui de Malleco, Chile. 1769-1776. Santiago: Dibam/Centro Barros Arana/ Lom Ediciones.

JARA, Álvaro (ed.). 1956. Legislación indigenista de Chile. México D.F.: Ediciones Especiales del Instituto Indigenista Interamericano.

Manquilef, Manuel. 1915. ;Las tierras de Arauco! Temuco: Imprenta Modernista.

Menard, André y Jorge Pavez. 2005. Los archivos del 29': derroteros y derrotas de la Federación Araucana. Anales de Desclasificación 1 (1): 51-70.

Menard, André. 2013. Estudio Preliminar: Manuel Aburto Panguilef y los archivos de la Federación Araucana. En Manuel Aburto. Libro Diario del Presidente de la Federación Araucana Manuel Aburto Panguilef, pp. XI-CXXX. Santiago: CoLibris. 
y Jorge Pavez (eds.). 2007. Mapuche y anglicanos. Vestigios fotográficos de la Misión Araucana de Kepe. Santiago: Ocho Libros.

Parentini, Luis Carlos. 1994. Tipos fronterizos en la Araucanía del siglo XIX: los afuerinos. Santiago: Documentos de Estudio Universidad Blas Cañas.

Pavez OJedA, JoRge. 2003. Mapuche ñinütramchilkatun/ Escribir la historia mapuche. Revista de Historia Indígena 7: 7-53.

(comp.). 2008. Cartas mapuche. Siglo XIX. Santiago: CoLibris/ Ocho Libros.

2015. Laboratorios etnográficos. Los archivos de la antropología en Chile (18801980). Santiago: Ediciones de la Universidad Alberto Hurtado.

PayÀs, GerTrudis y CARMEN GloRia Garbarini. 2012. La relación intérprete-mandante: claves de una crónica colonial para la historia de la interpretación. Onomazéin (25): 345-368.

Pinto, Jorge (ed.). 2014. Conflictos étnicos, sociales y económicos. Araucanía 1900-2014, Santiago: Pehuén Editores.

Robles Rodríguez, Eulogio. 1940. Costumbres y creencias araucanas. Santiago: Ediciones de la Universidad de Chile.

Treutler, Paul. 1861. La provincia de Valdivia i los Araucanos. Santiago: Imprenta Chilena. 1958 [1882]. Andanzas de un alemán en Chile. 1851-1863. Santiago: Editorial del Pacífico.

Ulloa Valenzuela, Fernando. 2009. Los españoles araucanos. Mediación y conflicto durante la Guerra a Muerte. Chile 1817-1825. Tesis para optar al grado de Licenciado en Historia, Universidad de Chile.

2020. ¿Mapuchización o erradicación? Trayectorias familiares y territoriales de capitanes de amigos y lenguaraces en Araucanía, 1825-1927. Tesis para optar al grado de Magíster en Historia, Universidad de Chile.

Vezub, Julio. 2009. Valentín Saygüeque y la "Gobernación Indígena de las Manzanas". Poder y Etnicidad en la Patagonia Septentrional (1860-1881). Buenos Aires: Prometeo Libros. E INGRID DE JONG. 2019. El giro escritural de la historiografía mapuche: alfabeto y archivos en las fronteras. Un estado de la cuestión. Quinto Sol 23 (3): 1-22.

Zavala, José Manuel. 2008. Los mapuches del siglo XVIII. Dinámica interétnica y estrategias de resistencia. Santiago: Ediciones de la Universidad Bolivariana. 